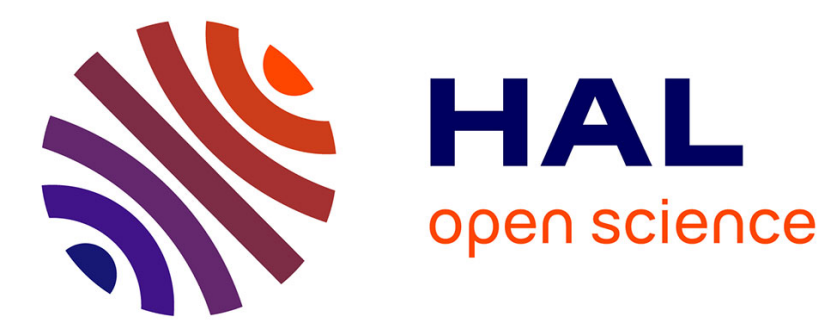

\title{
Cobalt-Mediated Radical Coupling (CMRC): An Unusual Route to Midchain-Functionalized Symmetrical Macromolecules
}

\author{
Antoine Debuigne, Rinaldo Poli, Julien De winter, Pascal Laurent, Pascal
} Gerbaux, Philippe Dubois, Jean-Paul Wathelet, Christine Jérôme, Christophe

Detrembleur

\section{To cite this version:}

Antoine Debuigne, Rinaldo Poli, Julien De winter, Pascal Laurent, Pascal Gerbaux, et al.. Cobalt-Mediated Radical Coupling (CMRC): An Unusual Route to Midchain-Functionalized Symmetrical Macromolecules. Chemistry - A European Journal, 2010, 16 (6), pp.1799-1811. 10.1002/chem.200902618 . hal-03178876

\section{HAL Id: hal-03178876 https://hal.science/hal-03178876}

Submitted on 24 Mar 2021

HAL is a multi-disciplinary open access archive for the deposit and dissemination of scientific research documents, whether they are published or not. The documents may come from teaching and research institutions in France or abroad, or from public or private research centers.
L'archive ouverte pluridisciplinaire HAL, est destinée au dépôt et à la diffusion de documents scientifiques de niveau recherche, publiés ou non, émanant des établissements d'enseignement et de recherche français ou étrangers, des laboratoires publics ou privés. 


\title{
Cobalt-Mediated Radical Coupling (CMRC) : An Unusual Route to Mid-chain- functionalized Symmetrical Macromolecules
}

\author{
Antoine Debuigne, ${ }^{*[a]}$ Rinaldo Poli, ${ }^{[b, c]}$ Julien De Winter, ${ }^{[\mathrm{d}]}$ Pascal Laurent, ${ }^{[\mathrm{e}]}$ Pascal Gerbaux, ${ }^{[\mathrm{d}]}$ \\ Philippe Dubois, ${ }^{[\mathrm{f}]}$ Jean-Paul Wathelet, ${ }^{[\mathrm{e}]}$ Christine Jérôme,${ }^{[\mathrm{a}]}$ Christophe Detrembleur ${ }^{[\mathrm{a}]}$
}

\begin{abstract}
Cobalt-Mediated Radical Coupling (CMRC) is a straightforward approach to the synthesis of symmetrical macromolecules which relies on the addition of 1,3-diene compounds onto polymer precursors preformed by Cobalt-Mediated Radical Polymerization (CMRP). Mechanistic features that make this process so efficient for radical polymer coupling are reported here. The mechanism was established on the basis of Nuclear Magnetic Resonance (NMR) and Matrix Assisted Laser Desorption Ionisation Mass Spectrometry
\end{abstract}

(MALDI-MS) analyses of the coupling product and corroborated by Density Functional Theory (DFT) calculations. A key feature of CMRC is the preferential insertion of two diene units in the middle of the chain of the coupling product mainly according to a trans-1,4-addition pathway. The large tolerance of CMRC towards the diene structure is demonstrated and the impact of this new coupling method on macromolecular engineering is discussed, especially for mid-chain functionalization of polymers. Noteworthy, the interest of CMRC goes beyond the field of polymer chemistry since it constitutes a novel carboncarbon bond formation method that could be applied to small organic molecules.

Keywords: radical coupling $\bullet$
diene $\bullet$ cobalt complex $\bullet$
poly $($ acrylonitrile $) \bullet$ controlled
radical polymerization

\section{Introduction}

[a] Dr. A. Debuigne, Prof. C. Jérôme, Dr. C. Detrembleur Center for Education and Research on Macromolecules University of Liège

Sart-Tilman, B6a, B-4000 Liège (Belgium)

Fax: (+32) 4-366 3497

E-mail: adebuigne@ulg.ac.be

[b] Prof. R. Poli

Laboratoire de Chimie de Coordination

University of Toulouse, UPS, INPT;

205, route de Narbonne, F-31077, Toulouse, France

[c] Prof. R. Poli

Institut Universitaire de France,

103, bd Saint-Michel, 75005 Paris, France,

[d] J. De Winter, Prof. P. Gerbaux

Mass Spectrometry Center, Organic Chemistry Laboratory,

University of Mons,

20, Place du Parc, 7000 Mons, Belgium

[e] Dr. P. Laurent, Prof. J.-P. Wathelet,

Unit of General and Organic Chemistry,

Gembloux Agricultural University (FUSAGx),

2, Passage des déportés, 5030 Gembloux, Belgium.

[f] Prof. P. Dubois,

Center of Innovation and Research in MAterials and Polymers (CIRMAP), Laboratory of Polymeric and Composite Materials,

University of Mons,

23, Place du Parc, 7000 Mons, Belgium.
Controlled radical polymerization (CRP) techniques give nowadays access to a large range of polymeric materials with well-defined molecular parameters such as low molar mass distributions, predictable molar masses and precise architectures. ${ }^{[1-11]}$ All these processes are based on the temporary deactivation of the growing radical species, which limits the extent of irreversible termination reactions that occur between radicals by coupling or disproportionation. Indeed, occurrence of termination during CRP is detrimental to the control of the molecular parameters and leads to materials with large and/or multimodal molar mass distributions. A notable exception to this rule is the case where termination is fast, quantitative and proceeds specifically by coupling. In that case, a perfect doubling of the polymer molar mass is expected without broadening of the molar mass distribution. Such a quantitative coupling process should be a powerful synthetic tool since $\alpha$ functional polymers and diblock copolymers should lead to the corresponding telechelic and triblock copolymers, respectively.

The first efficient radical coupling process reported in the literature is Atom Transfer Radical Coupling (ATRC). ${ }^{[2-18]}$ Typically, well-defined polymers formed by Atom Transfer Radical Polymerization (ATRP) have been added with copper catalysts and ligands in order to generate a large amount of radicals at once and to promote the coupling reaction. When applied to low molar mass precursors $(<5000 \mathrm{~g} / \mathrm{mol})$, the efficiency of the ATRC is generally 
above $90 \%$. However, moderate success was achieved when starting from polymers with high molar masses.

Recently, we reported a new radical coupling method, called Isoprene-Assisted Radical Coupling (I-ARC), ${ }^{[19]}$ consisting in addition of isoprene to polymer precursors formed by Cobalt Mediated Radical Polymerization (CMRP). As a reminder, CMRP is a CRP process based on the deactivation of the growing polymer species by cobalt complexes. ${ }^{[10]}$ It is efficient for controlling the homopolymerization of acrylates ${ }^{[20,21]}$, vinyl acetate $(\mathrm{VAc})^{[22-26]}, \mathrm{N}$ vinyl pyrrolidone (NVP) ${ }^{[27,28]}$ and acrylonitrile (AN) ${ }^{[29,30]}$ and is also a valuable approach for the preparation of block copolymers. However, addition of isoprene onto well-defined poly(acrylonitrile) (PAN) precursors, capped by bis(acetylacetonato)cobalt complexes $\left(\mathrm{Co}(\mathrm{acac})_{2}\right)$, exclusively leads to the coupling product (PAN- $b-$ PAN) instead of forming the poly(acrylonitrile)- $b$-poly(isoprene) (PAN-b-PIP) diblock copolymer by chain extension. ${ }^{[19]}$ In this case, the extent of coupling is above $95 \%$ even for PAN precursors with molar mass as high as $25000 \mathrm{~g} / \mathrm{mol}^{\left[{ }^{[19]}\right.}$ Moreover, I-ARC is the first radical coupling method that effectively leads to a symmetrical triblock copolymer when applied to a diblock precursor. For example, well-defined PVAc- $b$-PAN- $b$-PVAc copolymers have been prepared by I-ARC using PVAc- $b$-PAN-Co(acac $)_{2}$ diblock precursors. ${ }^{[19]}$ Although incorporation of few isoprene units in the coupling product was suggested in the first communication (Figure 1), this hypothesis suffered from lack of strong evidences until now.

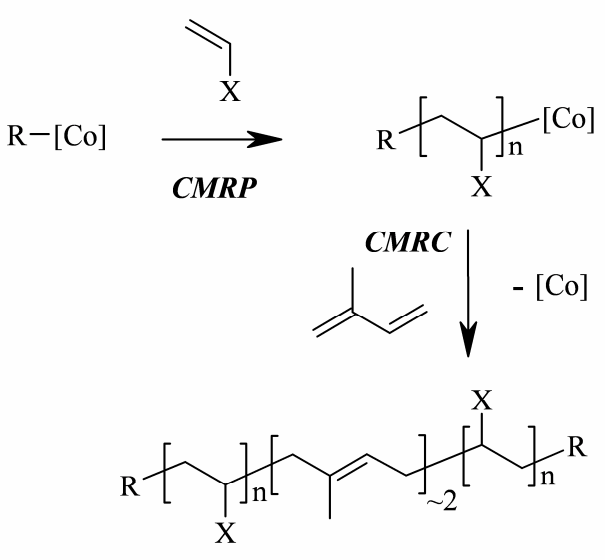

Figure 1. General scheme for the Cobalt-Mediated Radical Coupling (CMRC) method.

Here, we would like to elucidate the mechanistic features that make this process so efficient for radical coupling, to detail the structure of the junction between the two chains, and to illustrate the tolerance of this coupling method towards the structure of the diene coupling agent. A range of dienes, having different substitution degrees or bearing functional groups, are successfully used for the radical coupling of PAN-Co precursors. Nuclear Magnetic Resonance (NMR) and Matrix Assisted Laser Desorption Ionisation Mass Spectrometry (MALDI-MS) analyses of the coupling products reveal the insertion of very few diene units in the polymer and their location at the junction of the precursors is unambiguously demonstrated. This observation allows to progress in the understanding of this unusual coupling process and to go far beyond early elusive mechanistic proposals. Given the versatility of this coupling process towards the structure of the diene, the term I-ARC is clearly too restrictive. Moreover, it does not reflect the crucial role of the cobalt complex in the mechanism. Henceforth, the general term Cobalt-Mediated Radical Coupling (CMRC) will be preferred by analogy with ATRC. The impact of this new coupling method on macromolecular engineering, and more particularly for polymer functionalization, will also be highlighted.

\section{Results and Discussion}

Scope of Cobalt-Mediated Radical Coupling : As recently communicated, ${ }^{[19]}$ isoprene is a very efficient coupling agent for poly(acrylonitrile) prepared by CMRP and end-capped by a bis(acetylacetonato) cobalt complex. Given the crucial role played by the isoprene in this system, it is worth to evaluate the tolerance of CMRC towards various dienes used as coupling agents. In this study, linear and cyclic dienes having different substitution degree and bearing functionalities have been considered (see Figure 2).
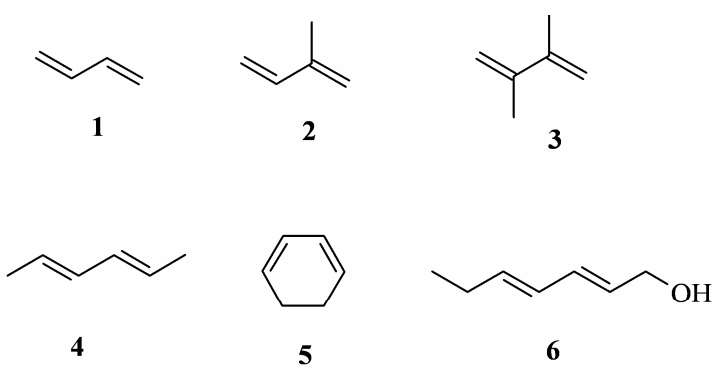<smiles>CC/C=C/C=C/COC(=O)c1ccccc1</smiles>

Figure 2. Dienes used as coupling agents for CMRC.

First, well-defined poly(acrylonitrile) precursors capped by bis(acetylacetonato) cobalt complex were prepared following the previously reported procedure. ${ }^{[29]}$ Typically, the controlled radical polymerization of acrylonitrile was initiated with an alkyl-cobalt(III) species $\left(\left[\mathrm{Co}(\mathrm{acac})_{2}\left(-\mathrm{CH}\left(\mathrm{OCOCH}_{3}\right) \mathrm{CH}_{2}\right)_{<4}-\mathrm{R}_{0}\right)\right]$ at $0^{\circ} \mathrm{C}$ (see Table 1) $\mathrm{By}$ adjusting the monomer/initiator molar ratio and the monomer conversion, two series of PAN precursors having molar masses around $4000 \mathrm{~g} / \mathrm{mol}$ and $12000 \mathrm{~g} / \mathrm{mol}$ were synthesized. In all cases, the molar mass distributions were very narrow. Noteworthy, better results were obtained using a DMF/DMSO mixture as solvent instead of pure DMSO for the synthesis of PAN with molar masses above $10000 \mathrm{~g} / \mathrm{mol}$.

After polymerization, the residual monomer was evaporated under reduced pressure and the PAN-Co(acac $)_{2}$ chains were treated with the diene. For each experiment, the extent of coupling $\left(\mathrm{x}_{\mathrm{c}}\right)$ was calculated as $x_{c}=2\left[1-\left(M_{n, 0} / M n\right)\right]$, where $M_{n, 0}$ and $M_{n}$ are the molar masses of the precursor and the coupling product, respectively. ${ }^{[14]}$ After repeating the previously described coupling reaction of the PAN chains with isoprene $2,{ }^{[19]}$ butadiene $\mathbf{1}$ was the most obvious candidate as coupling agent in the CMRC. The coupling process appeared nearly quantitative (extents of coupling close to unity) for both short and long polymer chains. The overlay of the SEC chromatograms of the reaction mixture before and after addition of butadiene exhibits a clear shift towards lower elution volume, thus higher molar masses (Figure 3A). The monomodal SEC profile for the final reaction mixture and the absence of tailing due to unreacted chains reflect the completeness of the coupling process. Next, we 
examined the effect of alkyl substituents (e.g. using dienes $\mathbf{3}$ and $\mathbf{4}$ ) on the coupling efficiency. An almost perfect doubling of the molar mass was again observed with both dienes. Thus, substitution at the diene 1,3 or 2,4 positions does not appear detrimental to the CMRC process. Good results were also obtained with cyclohexadiene $\mathbf{5}$. For example, a PAN having a molar mass of $7770 \mathrm{~g} / \mathrm{mol}$ was recovered after treatment of a precursor of $3890 \mathrm{~g} / \mathrm{mol}$. However, when the molar mass of the precursor was above $10000 \mathrm{~g} / \mathrm{mol}$ the calculated extent of coupling was slightly lower (90\%). Although the overlay of the SEC chromatograms, before and after coupling, appears very good at first sight, a discreet low molar mass population is observed at the base of the main peak (Figure 3B). It most probably corresponds to some unreacted PAN chains. Finally, experiments were conducted using functional dienes such as 2,4-heptadien-1-ol 6 and the corresponding esterified product, 2,4-heptadienyl benzoate 7 . The presence of an alcohol or an ester function on the coupling agent does not drastically alter the efficiency of the CMRC process (Figure 3C). Extents of coupling around 95\% were obtained. In addition to widening the range of the useful coupling agents for the $\mathrm{CMRC}$, these last two experiments are of prime importance for macromolecular engineering because they demonstrate the possibility of specific mid-chain functionalization. This point will be further discussed below.

Table 1. Cobalt-Mediated Radical Coupling (CMRC) reaction of polyacrylonitrile chains capped by $\mathrm{Co}(\mathrm{acac})_{2}$.

\begin{tabular}{|c|c|c|c|c|c|c|c|}
\hline \multirow[b]{2}{*}{$\begin{array}{l}\text { Diene } \\
\text { (Fig. 2) }\end{array}$} & \multicolumn{3}{|c|}{ PAN-[Co] Precursor } & \multicolumn{3}{|c|}{ Coupling product } & \multirow[b]{2}{*}{$x_{\mathrm{c}}^{[\mathrm{b}]}$} \\
\hline & $\begin{array}{l}\mathbf{M}_{\mathrm{n}, 0}{ }^{[\mathrm{a}]} \\
{[\mathrm{g} / \mathrm{mol}]}\end{array}$ & $\begin{array}{l}\mathrm{M}_{\mathrm{p}, 0}{ }^{[\mathrm{a}]} \\
{[\mathrm{g} / \mathrm{mol}]}\end{array}$ & $\begin{array}{c}\mathrm{M}_{\mathrm{w}} / \\
\mathrm{M}_{\mathrm{n}}\end{array}$ & $\begin{array}{c}\left.\mathrm{M}_{\mathrm{n}}{ }^{\mathrm{a}]}\right] \\
{[\mathrm{g} / \mathrm{mol}]}\end{array}$ & $\begin{array}{c}\mathrm{M}_{\mathrm{p}}^{[\mathrm{a}]} \\
{[\mathrm{g} / \mathrm{mol}]}\end{array}$ & $\begin{array}{c}\mathrm{M}_{\mathrm{w}} / \\
\mathrm{M}_{\mathrm{n}}\end{array}$ & \\
\hline \multirow{2}{*}{1} & 4080 & 4320 & 1.02 & 7990 & 8650 & 1.02 & 0.98 \\
\hline & 11000 & 11000 & 1.02 & 21200 & 21600 & 1.01 & 0.96 \\
\hline \multirow{2}{*}{2} & 4320 & 4500 & 1.02 & 8320 & 8990 & 1.02 & 0.96 \\
\hline & 11800 & 11700 & 1.03 & 22100 & 22600 & 1.01 & 0.93 \\
\hline \multirow{2}{*}{3} & 3000 & 3100 & 1.01 & 6000 & 5800 & 1.02 & 1.00 \\
\hline & 13400 & 13100 & 1.01 & 24100 & 24400 & 1.01 & 0.89 \\
\hline \multirow{2}{*}{4} & 3100 & 3250 & 1.01 & 6200 & 6500 & 1.01 & 1.00 \\
\hline & 11900 & 12200 & 1.03 & 22300 & 22700 & 1.01 & 0.93 \\
\hline \multirow{2}{*}{5} & 3890 & 4150 & 1.03 & 7770 & 8400 & 1.02 & 1.00 \\
\hline & 13900 & 13700 & 1.04 & 25100 & 25800 & 1.03 & 0.90 \\
\hline \multirow{2}{*}{6} & 3320 & 3460 & 1.01 & 6450 & 7060 & 1.02 & 0.97 \\
\hline & 11000 & 10800 & 1.02 & 21100 & 22700 & 1.03 & 0.96 \\
\hline & 2800 & 3300 & 1.10 & 4700 & 5900 & 1.15 & 0.81 \\
\hline & 11400 & 11200 & 1.02 & $21500^{[\mathrm{c}]}$ & 22800 & 1.03 & 0.94 \\
\hline
\end{tabular}

[a] Determined by SEC-MALLS in DMF ((dn/dc) but one that was determined by SEC using a PMMA calibration corrected by the MarkHouwink equation. $[\mathrm{b}]$ Extent of coupling $=x_{\mathrm{c}}=2\left[1-\left(\mathrm{M}_{\mathrm{n}, 0} / \mathrm{M}_{\mathrm{n}}\right)\right]^{[14]}$. Conditions for polymer precursors below $5000 \mathrm{~g} / \mathrm{mol}$; Polymerization : [Co(acac $)_{2}(-$ $\left.\left.\left.\mathrm{CH}\left(\mathrm{OCOCH}_{3}\right) \mathrm{CH}_{2}\right)_{<4}-\mathrm{R}_{0}\right)\right]$ as initiator $(0.12 \mathrm{mmol})$, AN (38 mmol), DMSO as solvent $(\mathrm{DMSO} / \mathrm{AN}=1 / 1(\mathrm{v} / \mathrm{v})), 0^{\circ} \mathrm{C}, 4 \mathrm{~h}$, monomer convn. $=17-21 \%$. Coupling $:$ diene $(5.0$ mmol), r.t., $2 \mathrm{~h}$. Conditions for polymer precursors above $10000 \mathrm{~g} / \mathrm{mol}$; Polymerization : $\left.\left[\mathrm{Co}(\mathrm{acac})_{2}\left(-\mathrm{CH}\left(\mathrm{OCOCH}_{3}\right) \mathrm{CH}_{2}\right)_{<4}-\mathrm{R}_{0}\right)\right]$ as initiator $(0.09 \mathrm{mmol})$, AN (38 mmol), DMSO/DMF mixture as solvent (DMSO/DMF/AN $=0.5 / 0.5 / 1(\mathrm{v} / \mathrm{v} / \mathrm{v})), 0^{\circ} \mathrm{C}$, $24 \mathrm{~h}$, monomer convn. $=33-38 \%$. Coupling : dilution with DMF $\left(\mathrm{V}_{\mathrm{DMSO}} / \mathrm{V}_{\mathrm{DMF}}=0.4\right.$, addition of diene $(5.0 \mathrm{mmol})$ at r.t., $2 \mathrm{~h}$. [c] $2.5 \mathrm{mmol}$ of 2,4-heptadienyl benzoate 7 was used.
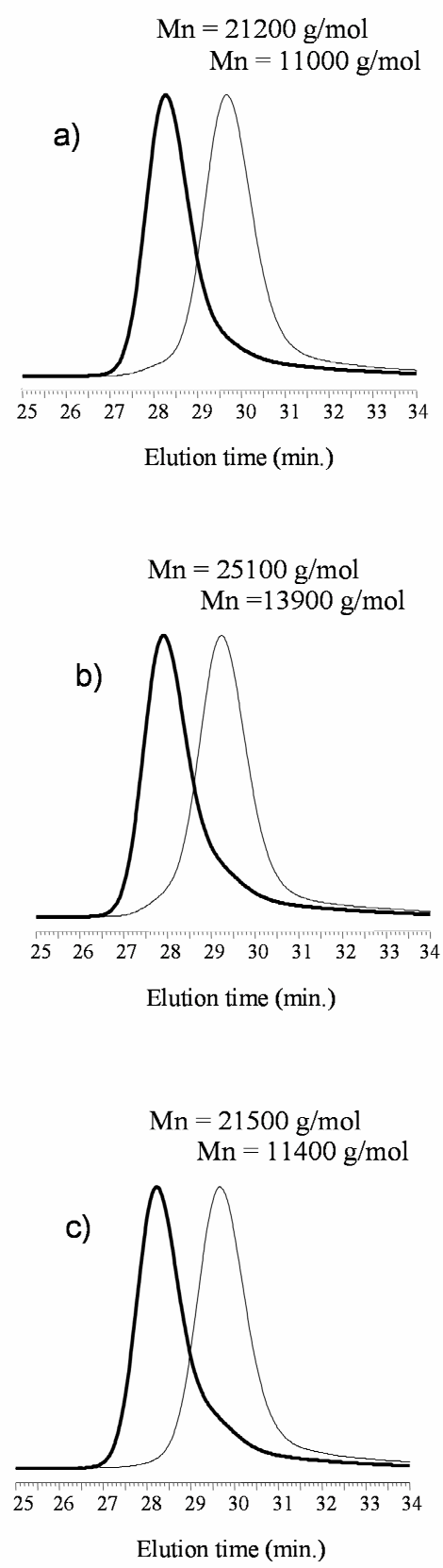

Figure 3. Size-exclusion chromatograms (RI) of the PAN-[Co] precursors prepared from a CMRP initiator (full line) and the resulting coupling product (bold line) upon treatment with butadiene1 (a), 1,3-cyclohexadiene 5 (b) and 2,4-heptadienyl benzoate 7 (c).

1D-NMR study : In order to dispel any doubt about the insertion of diene during the coupling process and to address the CMRC mechanism, 1D- ${ }^{1} \mathrm{H}$ NMR analyses were carried out on the coupling product obtained with each diene. The lower molar mass poly(acrylonitrile) samples were preferred in order to facilitate the detection of the significant protons at the junction of the PAN precursor chains. In all cases, very intense signals were detected at $\delta$ 3.2 and 2.1, corresponding to the methyne and methylene protons of the PAN main chain, respectively. Smaller signals also appeared in all spectra at $\delta$ 5.3-4.2 and 1.4-1.1 (see Figure 4), corresponding respectively to the methyne and methyl protons issued from the cobalt(III) initiating species $\left(\left[\mathrm{Co}(\mathrm{acac})_{2}-\left(\mathrm{C} \underline{\mathrm{H}}(\mathrm{OAc}) \mathrm{CH}_{2}\right)_{<4^{-}}\right.\right.$ $\left.\left.\mathrm{C}\left(\mathrm{CH}_{3}\right)(\mathrm{CN})-\mathrm{CH}_{2}-\mathrm{C}\left(\mathrm{OCH}_{3}\right)\left(\mathrm{CH}_{3}\right)_{2}\right)\right]$. Integration of these signals 
confirmed that the initiator contains an average number of four vinyl acetate units.

In addition to the above signals, assigned to the PAN precursors, other small diene-specific signals were detected, proving the incorporation of a tiny amount of diene in the polymer (see Figure 4). For example, small signals were detected in the vinylic region of the PAN sample recovered after coupling with butadiene. Similarly, signals typical of poly(isoprene) were detected in the vinylic and allylic regions when isoprene was used. Based on typical signals in the aliphatic, allylic, vinylic and aromatic region, it is possible to conclude that incorporation of diene occurred in each case. Note that only the 1,4-trans-addition products are represented in Figure 4 . The question of the regio- and stereo-chemistry of the mid-chain unsaturations has been addressed by two-dimensional NMR analyses (see later). The relative intensities of the olefinic and/or allylic protons assigned to the inserted diene units and those of the poly(acrylonitrile) protons gave access to the average number of diene units per chain in the coupling product which is generally close to two (Figure 4). The use of functionalized dienes in the CMRC process thus appears as an interesting approach to introduce functions selectively in the middle of a polymer backbone.

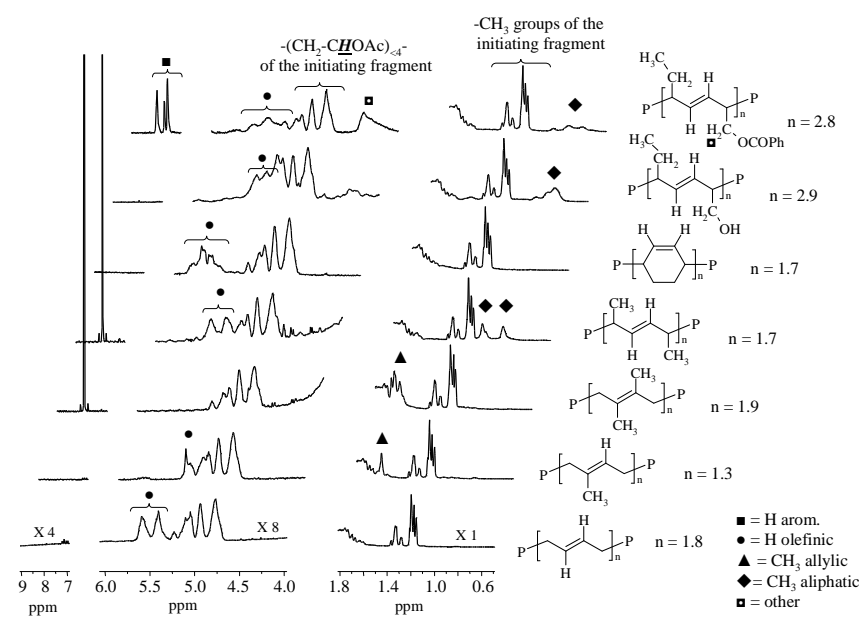

Figure 4. Overlay of the $1 \mathrm{D}-{ }^{1} \mathrm{H}$ NMR spectra of the PAN coupling products. The number of diene units incorporated in the coupling products (n) is determined by comparison of intensities of signals typical of the PAN main chain (whose molar mass is determined by MALLS) and olefinic or allylic protons of the coupling species (for a typical example of full NMR spectrum of PAN see supporting information Figure A)

MALDI-ToF Mass Spectrometry Analysis : Before discussing the mechanism of the polymerization reaction, it is obviously of prime importance to establish the distribution of diene units inserted during the CMRC process. This piece of information is likely to be derived from MALDI-ToF measurements on the polymer coupling product. In order to facilitate the spectral interpretation and clearly evidence the number of inserted diene units, the coupling agent and initiator were carefully selected to inter alia avoid isobaric interferences. First of all, the alkyl-cobalt(III) reagent ([Co(acac) $)_{2}(-$ $\left.\left.\left.\mathrm{CH}\left(\mathrm{OCOCH}_{3}\right) \mathrm{CH}_{2}\right)_{\sim 4}-\mathrm{R}_{0}\right)\right]$ was excluded because it consists of a distribution of PVAc oligomers. Indeed, the simultaneous presence of two molecular mass distributions (VAc and AN) would probably render the determination of the amount of inserted diene units extremely complex since the mass spectrum would definitively be more crowded. Secondly, the use of butadiene as the coupling agent is not appropriate since its molecular mass $(54 \mathrm{u})$ is too close to that of the acrylonitrile repeating unit $(53 \mathrm{u})$. As a direct consequence, populations with a different numbers of diene units would overlap, complicating the determination of the number of incorporated butadiene residues. Taking these considerations into account, the poly(acrylonitrile) specifically prepared for the MALDI analysis was obtained using V-70 as the initiator. This reagent provides an initiating fragment with a non interfering molecular mass $(140 \mathrm{u})$. Finally, isoprene $(68 \mathrm{u})$ was selected as the coupling agent. Although the molecular mass distribution of the so-obtained PAN polymer was larger $\left(\mathrm{M}_{\mathrm{w}} / \mathrm{M}_{\mathrm{n}} \sim 1.2\right)$ than that of the polymer obtained starting with the alkyl-cobalt(III) species, the mass spectrometry data were by far easier to analyze. For the sake of information, a clear shift of the SEC chromatograms was also observed towards higher molecular masses upon treatment with isoprene (Figure 5). This observation is consistent with data here above presented.

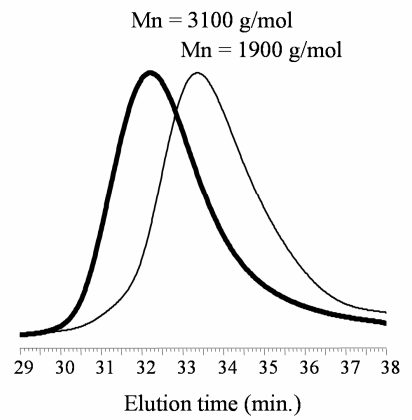

Figure 5. Size-exclusion chromatograms (RI) of the PAN-[Co] precursor prepared from $\mathrm{Co}(\mathrm{acac})_{2}$ and V-70 (full line) and the resulting coupling product upon treatment with isoprene (bold line).

Several experimental conditions were tested in order to optimize the MALDI analysis of the PAN sample. Various matrices [cyano-4hydroxycinnamic acid (CHCA), trans-2-[3-\{4-tert-butylphenyl $\}-2-$ methyl-2-propenylidene]malononitrile (DCTB), dithranol, trans-3(3-indolyl)acrylic acid and 4-hydroxybenzylidene malononitrile] and different cationizing agents (sodium, copper or silver salts) were tested. In general, the sensitivity was poor, except when 4hydroxybenzylidene malononitrile was associated with $\mathrm{NaI}$, in agreement with a previous report. ${ }^{[31]}$ Figure $6 \mathrm{~A}$ shows a typical MALDI spectrum acquired under those conditions for the PAN coupling product. At a first glance, one ion series clearly emerges and presents a $53 \mathrm{u}$ interval that undoubtedly corresponds to the residual mass of AN. The fast decreasing profile of the distribution and the lower value of $M_{n}$ measured by MALDI-MS as compared to the SEC-MALLS determined value is ascribed to easier desorption/ionization of shorter polyacrylonitrile chains. In the enlargement of the MALDI spectrum (Figure 6B), the most intense detected population corresponds to sodium-cationized PAN coupling product constituted by two isoprene units $\left(\mathrm{X}_{2}\right)$ in its backbone. As an example, the peak detected at $\mathrm{m} / \mathrm{z} 1183$ was attributed to a sodium-cationized oligomer constituted by fourteen acrylonitrile $(\mathrm{Y})$ units together with two isoprene $(\mathrm{X})$ units $\left(\mathrm{Y}_{14} \mathrm{X}_{2}\right)$. Nevertheless, a 2 u mass difference is observed between the experimental data and the theoretical isotope model $(\mathrm{m} / \mathrm{z}, 1181$ for $\mathrm{Y}_{14} \mathrm{X}_{2}{ }^{\mathrm{Na}+}$ ) as revealed in Figure 6C. It is reasonable to assume that this discrepancy of $2 \mathrm{u}$ arises from a hydrogenation reaction of the coupling product during the ionization process in the presence of 4hydroxybenzylidene malononitrile. On the basis of this putative reduction reaction, a novel isotope model was generated for 
$\mathrm{Y}_{14} \mathrm{X}_{2} \mathrm{H}_{2}{ }^{\mathrm{Na}+}$ and, as presented in Figure 6C, this experimental isotope pattern is now perfectly in agreement with the theoretical one.

A)

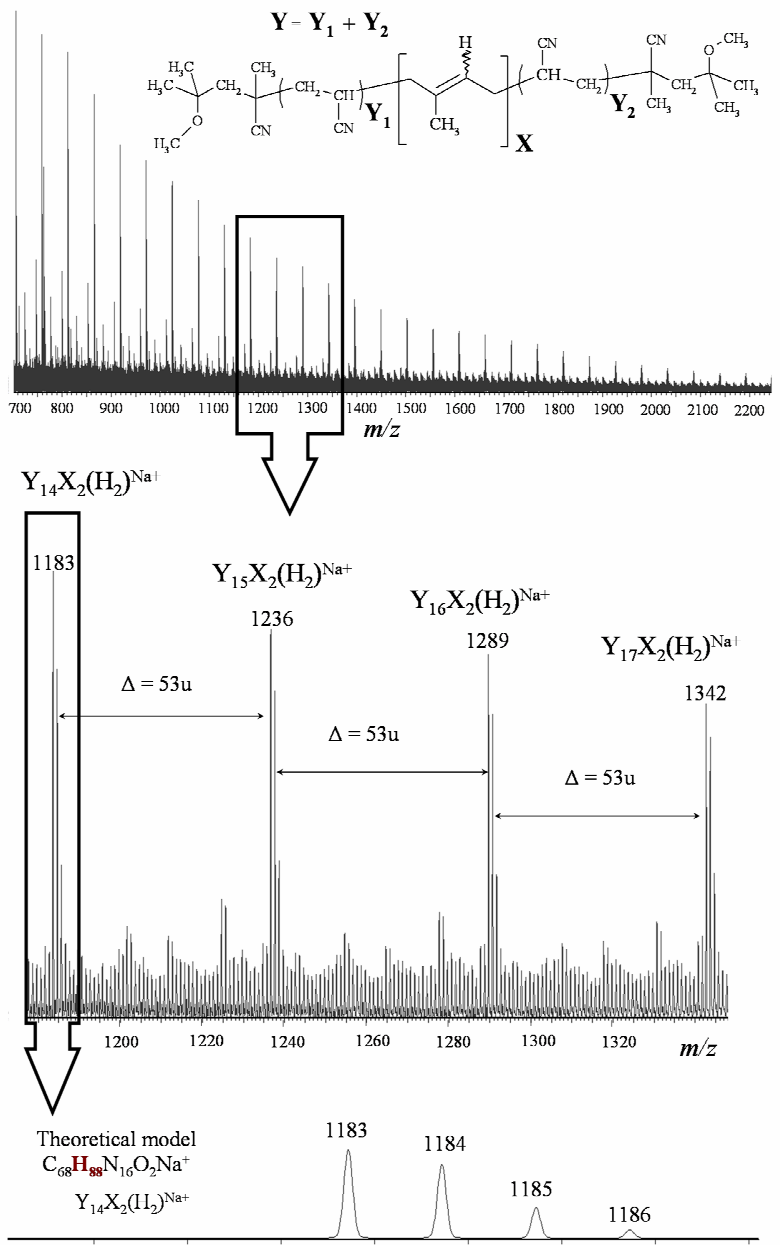

B)

C)
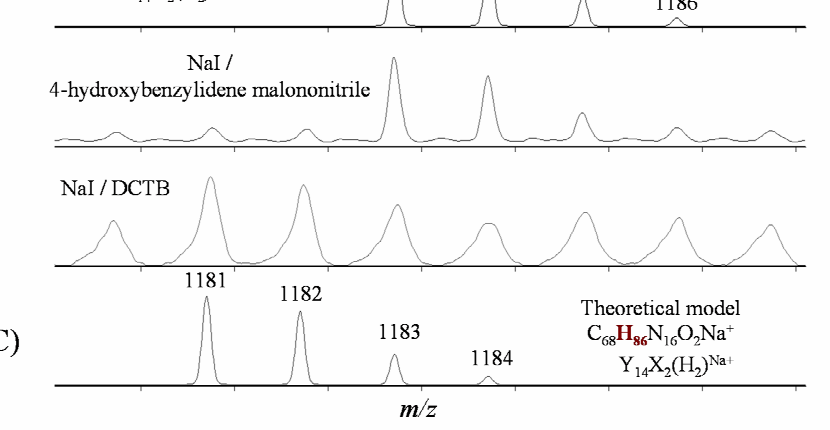

Figure 6. (A) MALDI-ToF mass spectrum (matrix: 4-hydroxybenzylidene malononitrile; cationization agent : NaI) of a poly(acrylonitrile) sample prepared by CMRP from V-70 and bis-(acetylateconato)cobalt(II) followed by coupling with isoprene. (B) Enlarged region $(\mathrm{m} / \mathrm{z}, 1280-1340)$ of the mass spectrum. (C) Comparison between experimental data and theoretical isotope patterns for $\mathrm{C}_{68} \mathrm{H}_{88} \mathrm{~N}_{16} \mathrm{O}_{2}{ }^{\mathrm{Na}}$ and $\mathrm{C}_{68} \mathrm{H}_{86} \mathrm{~N}_{16} \mathrm{O}_{2}{ }^{\mathrm{Na}+}$.

Hydrogenation/reduction processes upon MALDI were recently observed and studied and were generally detected when using the so-called reductive matrices. For instance, the use of 2,5dihydroxybenzoic acid (DHB) $)^{[32]}$ and 1,5-diaminonaphtalene $(\mathrm{DAN})^{[33]}$ as MALDI matrices were shown to induce hydrogenation reactions. In the case of DHB, the reduction process was proposed to occur through hydrogen atom transfer from one of the hydroxylic groups of the matrix molecule to the analyte. ${ }^{[32]}$ The presence of such a phenolic hydrogen atom on the matrix used in our measurement, namely 4-hydroxybenzylidene malononitrile, is then consistent with the observation of the proposed hydrogenation process. In order to test this hypothesis, we measured the MALDIToF mass spectrum of the same polymer with DCTB as the matrix, using $\mathrm{NaI}$ as the cationization agent. Even if the recorded mass spectrum is characterized by a poor signal-to-noise $\mathrm{S} / \mathrm{N}$ ratio, this spectrum definitively confirms that the hydrogenation process is matrix-dependent (Figure 6C). All those results clearly point to the importance of the experimental conditions (matrix and cationization agent) upon the nature of the observed ions starting with a given analyte.

Figures $6 \mathrm{~A}$ and $6 \mathrm{~B}$ also present some minor populations barely emerging from the noise of the spectrum. Those ion series could correspond to PAN containing three, four and five isoprene units. However, the really poor signal-to-noise ratio represents an obstacle to a totally certain identification. In order to improve the $\mathrm{S} / \mathrm{N}$ ratio of the MALDI spectrum, we replaced sodium iodide by copper chloride as the cationization agent, given the fact that copper ions are known to be excellent cationization agents for poly(isoprene). ${ }^{[31]}$ However, under these conditions, the $\mathrm{S} / \mathrm{N}$ ratio remains weak and the ion series constituted by ionized oligomers containing two isoprene units remains the dominant population in the MALDI spectrum (see Figures B and C in the supporting information).

On the other hand, species containing only one or no isoprene unit were never detected whatever the choice of matrix/cationization agent. For example, coupling products containing no isoprene $\left(\mathrm{Y}_{18} \mathrm{X}_{0}{ }^{\mathrm{Na}+}\right.$ at $\left.\mathrm{m} / \mathrm{z}, 1257\right)$ or only one unit $\left(\mathrm{Y}_{16} \mathrm{X}_{1}{ }^{\mathrm{Na}+}\right.$ at $\mathrm{m} / z, 1219 \mathrm{~m} / \mathrm{z}$ or $\mathrm{Y}_{16} \mathrm{X}_{1}\left(\mathrm{H}_{2}\right)^{\mathrm{Na}+}$ at $\mathrm{m} / \mathrm{z}$. 1221) were definitively absent in the MALDI spectrum (Figure 6B). In this respect, CMRC is completely different from ATRC which relies on the direct coupling of the polymer precursors without insertion of any compound at the junction of the chains. ${ }^{[12-14]}$

The high tendency of the CMRC to promote specific insertion of two diene units in the polymer is unique and makes it a promising tool for precise mid-chain functionalization. Moreover, this characteristic constitutes a serious clue for the mechanistic investigations developed below.

2D-NMR study : In the perspective to approach the CMRC mechanism, it is essential to define the addition modes $(1,4$ vs. 1,2$)$ of the diene as well as the stereochemistry of the resulting unsaturations. This information was provided by two-dimensional Heteronuclear Single Quantum Coherence (HSQC) and Heteronuclear Multiple Bond Correlation (HMBC) NMR experiments carried out on the product recovered after coupling with butadiene (see Table 1, entry 1).

A section of the HSQC spectrum (Figure 7A) reveals cross peaks for $\mathrm{H}_{\mathrm{a}}\left(\delta\right.$ 5.2-4.6) and $\mathrm{C}_{1}(\delta 69)$, which can be unambiguously assigned to the signal corresponding to $-\underline{\mathrm{CH}}(\mathrm{OAc})$ - groups of the initiating fragment. Other evident correlations, designated by HSQC as $\mathrm{CH}$ groups, are observed between $\mathrm{H}_{\mathrm{c}}(\delta 5.40)$ and $\mathrm{C}_{4}(\delta 124)$ and between $\mathrm{H}_{\mathrm{d}}(\delta 5.55)$, and $\mathrm{C}_{5}(\delta 133)$. These chemical shifts are typical of alkene proton and carbon nuclei and correspond to $-\mathrm{CH}=$ groups resulting from the polymer inserted butadiene. Based on the chemical shifts, the $\mathrm{C}_{4}$ and $\mathrm{C}_{5}$ signals can also be clearly assigned to the 1,4 -addition product. ${ }^{[34-36]}$ Smaller correlations were also observed between $\delta 5.05\left(\delta_{\mathrm{H}}\right)$ and $\delta 117\left(\delta_{\mathrm{C}}\right)$ and between $\delta$ 5.5-5.6 $\left(\delta_{\mathrm{H}}\right)$ and $\delta 140\left(\delta_{\mathrm{C}}\right)$. According to the HSQC spectrum, they correspond to $\mathrm{CH}_{2}$ and $\mathrm{CH}$ groups, respectively, of pendant vinyl groups resulting from the 1,2-addition mode $\left(-\mathrm{CH}=\mathrm{CH}_{2}\right)$. Considering the intensities of these signals, insertion of diene via the 
1,2-addition mode appears to be very limited in the CMRC process compared to the 1,4-addition pathway.

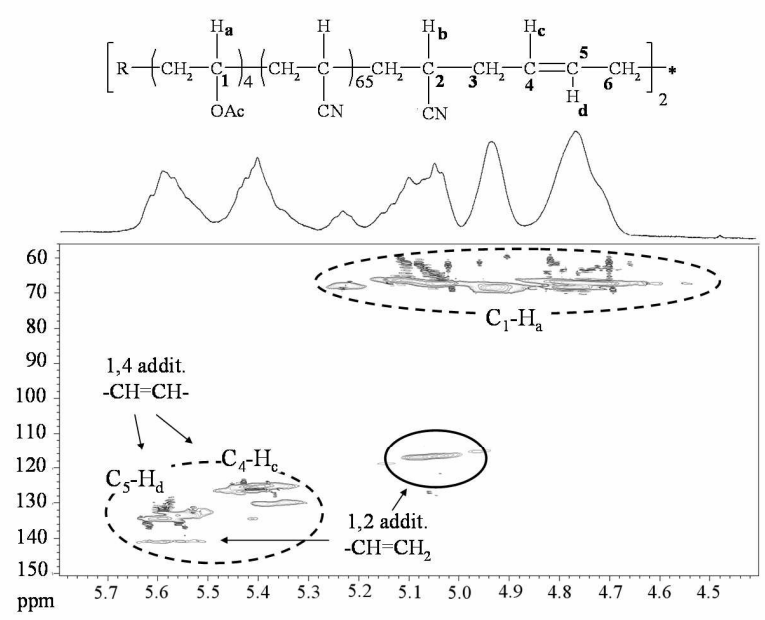

a)
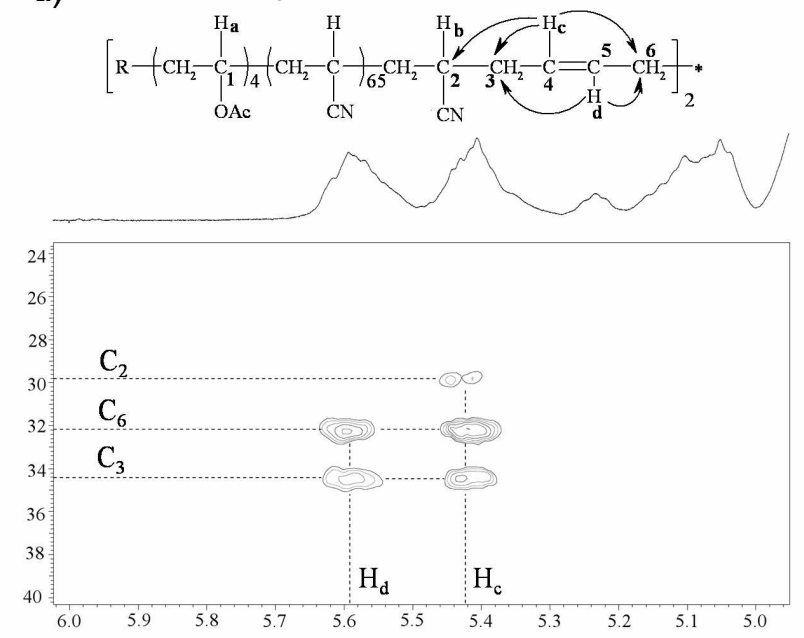

b)

ppm

Figure 7. Enlarged regions of HSQC (a) and HMBC (b) spectra of a poly(acrylonitrile) sample after coupling reaction with butadiene (preparation, see table 1 entry 1 ). In spectrum (a), cross-coupling signals circled by a full line and a dotted line correspond to a $\mathrm{CH}_{2}$ and $\mathrm{CH}$ groups, respectively.

Furthermore, an HMBC experiment was carried out not only in order to confirm the assignments of HSQC but also to determine the double bond stereochemistry in the major 1,4-addition product (Figure 7B). Indeed, HMBC shows the long range ${ }^{1} \mathrm{H}-{ }^{13} \mathrm{C}$ correlations of the vinyl proton $\mathrm{H}_{\mathrm{d}}(\delta 5.59)$ with allylic carbons $\mathrm{C}_{3}$ $(\delta 34)$ and $\mathrm{C}_{6}(\delta 32)$, whereas $\mathrm{H}_{\mathrm{c}}$ exhibits an extra correlation with a carbon at $30 \mathrm{ppm}$ which corresponds to the carbon $\mathrm{C}_{2}$ of the last $\mathrm{AN}$ unit of the precursor. Finally, chemical shifts of the allylic carbon atoms are typical of the $E$-isomer (above $30 \mathrm{ppm}$ ) whereas the $Z$ isomer generally yields resonances around $27 \mathrm{ppm} .^{[34-36]}$

Based on the NMR and MALDI analyses of the coupling products, it is possible to conclude that most polymer chains recovered after the CMRC process contain two diene units inserted preferentially via the 1,4-trans-addition pathway. This information is a keystone in the mechanistic discussion below.

Mechanistic considerations : In the absence of diene monomer, the $\mathrm{Co}(\mathrm{acac})_{2}(\mathrm{PAN})$ dormant chains are in rapid equilibrium with
$\mathrm{Co}(\mathrm{acac})_{2}$ and free PAN radical chains. The latter can either $(i)$ recombine with $\mathrm{Co}(\mathrm{acac})_{2}$ leading again to the dormant state, or (ii) undergo bimolecular terminations (suppressed by the persistent radical effect), or (iii) add a new AN molecule to propagate the chain, followed again by trapping, by the improbable termination, or by further growth.

The addition of the diene monomer changes the picture because monomer addition transforms a cyanocarbyl-type radical to an allyltype radical. This addition reaction should be quite favourable considering the reactivity ratios of the radical polymerization of AN and $\mathrm{B}\left(\mathrm{r}_{1}=0.03\right.$ and $\left.\mathrm{r}_{2}=0.2\right),{ }^{[37]}$ showing a great propensity of cross-propagation from the cyanocarbyl to the allyl radical. The new radical is now faced with the same three possibilities: $(i)$ combine with $\mathrm{Co}(\mathrm{acac})_{2}$ to yield a new dormant organometallic species; (ii) undergo bimolecular terminations; or (iii) further add diene monomer molecules. Addition of acrylonitrile to come back to a $\mathrm{PAN}^{\circ}$-type radical is not an option, because the diene was added after removal of the residual AN monomer.

The experimental evidence of a strong preponderance of coupled polymer chains containing two diene units suggests that further monomer addition is slow relative to the other two processes. The question then concerns whether the allyl-terminated radical chains, obtained after the first diene addition (for instance, PAN$\mathrm{CH}_{2}-\mathrm{CH}=\mathrm{CH}=-\mathrm{CH}_{2}{ }^{\circ}$ in case of butadiene), can be transformed into a sufficiently stable $\mathrm{Co}(\mathrm{acac})_{2}$-capped dormant chain or not. This question has been addressed at the computational level.

DFT Calculations : Previous work has demonstrated the value of DFT calculations for the rationalization of various phenomena in CMRP. ${ }^{[26,29,38]}$ Specifically, the homolytic bond dissociation enthalpy (BDE) of the $\mathrm{Co}^{\mathrm{III}}$-bond in the dormant organometallic species of both vinyl acetate and acrylonitrile CMRP was found to be located in a suitable intermediate range, not too high allowing a sufficiently rapid generation of free radicals and not too low insuring a low free radical concentration, and consequently negligible bimolecular terminations, under the persistent radical effect. The effect of donor solvent molecules $\mathrm{L}$ on the effective polymerization rate could also be rationalized. ${ }^{[24,29,38]}$ These molecules affect the rate by shifting the activation/deactivation equilibrium through coordination of both the $\mathrm{Co}^{\mathrm{III}}$ center in the dormant state, yielding $\mathrm{L}(\mathrm{acac})_{2} \mathrm{Co}^{\mathrm{III}}$-polymer, and the $\mathrm{Co}^{\mathrm{II}}$ deactivator, yielding $\mathrm{Co}(\mathrm{acac})_{2}(\mathrm{~L})_{2}$.

The nature of the dormant chains in the present system, prior to diene addition to induce the coupling process, is $(\mathrm{L})(\mathrm{acac})_{2} \mathrm{Co}^{\mathrm{III}}$ PAN where $\mathrm{L}$ is either DMF or DMSO. Calculations on this system have been reported previously, ${ }^{[29]}$ with -PAN being modelled by the short alkyl chain $-\mathrm{CH}(\mathrm{CN}) \mathrm{CH}_{3}$ (the polymer chain beyond the first monomer unit is replaced by a $\mathrm{H}$ atom for computational efficiency). It was found that DMSO is slightly better than DMF as a ligand for $\mathrm{Co}^{\mathrm{II}}(\mathrm{acac})_{2}$, whereas the opposite is true for $\mathrm{Co}^{\mathrm{III}}(\mathrm{acac})_{2}(\mathrm{PAN}) .^{[29]}$ The most important result of the previous study was the need to use the ad hoc functional B3PW91* with a reduced Hartree-Fock exchange contribution in order to obtain reasonable values for the enthalpy of the activation equilibrium (from $\mathrm{Co}^{\mathrm{III}}(\mathrm{acac})_{2}(\mathrm{~L})\left(\mathrm{CH}(\mathrm{CN}) \mathrm{CH}_{3}\right)+\mathrm{L}$ to $\mathrm{Co}^{\mathrm{II}}(\mathrm{acac})_{2}(\mathrm{~L})_{2}+\mathrm{CH}_{3} \mathrm{CH}(\mathrm{CN})^{*}$ : $9.2 \mathrm{kcal} / \mathrm{mol}$ for $\mathrm{L}=\mathrm{DMF}$; $6.6 \mathrm{kcal} / \mathrm{mol}$ for $\mathrm{L}=\mathrm{DMSO})$. When using the more popular B3LYP, the calculated bond strengths were too low to be in agreement with the experimentally observed efficient reversible trapping of the PAN radical chains.

We focussed initially on the $\mathrm{Co}^{\mathrm{III}}-\mathrm{R}$ BDE in the absence of solvent. Using the same computational level of the previous study, we have calculated the $\mathrm{BDE}$ between the $\mathrm{Co}(\mathrm{acac})_{2}$ complex and the 
allyl radical $\mathrm{CH}_{3} \mathrm{CH}=-\mathrm{CH}=--\mathrm{CH}_{2}{ }^{\circ}$, taken as a model of the PAN- $\mathrm{CH}_{2} \mathrm{CH}=\mathrm{CH}=\mathrm{CH}_{2}{ }^{\circ}$ radical chain. The results are compared with those of the corresponding $\mathrm{PAN}^{*}$ model in Figure 8. $\eta^{1}$ coordination of the allyl radical can occur in two different ways, binding either the terminal (primary) carbon atom or the internal (secondary) one, in both cases leading to a 5-coordinate square pyramidal configuration with the alkyl group in the axial position. Binding the terminal carbon atom leads, as expected, to the more stable product, stabilized by only $4.5 \mathrm{kcal} / \mathrm{mol}$ relative to the separate $\mathrm{Co}(\mathrm{acac})_{2}$ and allyl radical. This stabilization is ca. 2 $\mathrm{kcal} / \mathrm{mol}$ weaker than that associated to the $\mathrm{CH}_{3} \mathrm{CH}(\mathrm{CN})^{-}$radical, model of the $\mathrm{PAN}^{*}$ chain $(6.7 \mathrm{kcal} / \mathrm{mol})$. Binding the internal carbon atom is endothermic. In principle, one way to stabilize the system would be to rearrange the allyl ligand from $\eta^{1}$ to $\eta^{3}$ coordination, leading to an electronically saturated system. However, unexpectedly, the $\mathrm{Co}^{\mathrm{III}}(\mathrm{acac})_{2}\left(\eta^{3}-\mathrm{C}_{4} \mathrm{H}_{7}\right)$ derivative has in fact higher enthalpy than the 16-electron $\mathrm{Co}{ }^{\mathrm{III}}(\mathrm{acac})_{2}\left(\eta^{1}-\mathrm{CH}_{2} \mathrm{CH}=\mathrm{CHCH}_{3}\right)$. Each system was computed in the expected most stable stereoisomer (syn isomer for the $\eta^{3}$ coordination, $E$ isomer for the $\eta^{1}$ coordination). Indeed, optimization of the $\eta^{3}$ anti isomer $\left(\mathrm{CH}_{3}\right.$ substituent anti relative to the central allyl $\mathrm{H}$ atom) leads to a local minimum ca. $5 \mathrm{kcal} / \mathrm{mol}$ higher in enthalpy relative to the syn isomer. The reason for this unexpected result is attributed to the less favourable cis arrangement of the two acetylacetonate ligands, required to accommodate the $\eta^{3}$-allyl ligand, relative to the trans arrangement adopted in the square pyramidal 5-coordinate geometry. The weak energetic gain associated to the coordination of the soft $\mathrm{C}=\mathrm{C} \pi$ electrons to the hard $\mathrm{Co}^{\mathrm{III}}$ center is apparently insufficient to compensate for the cost of this structural rearrangement.

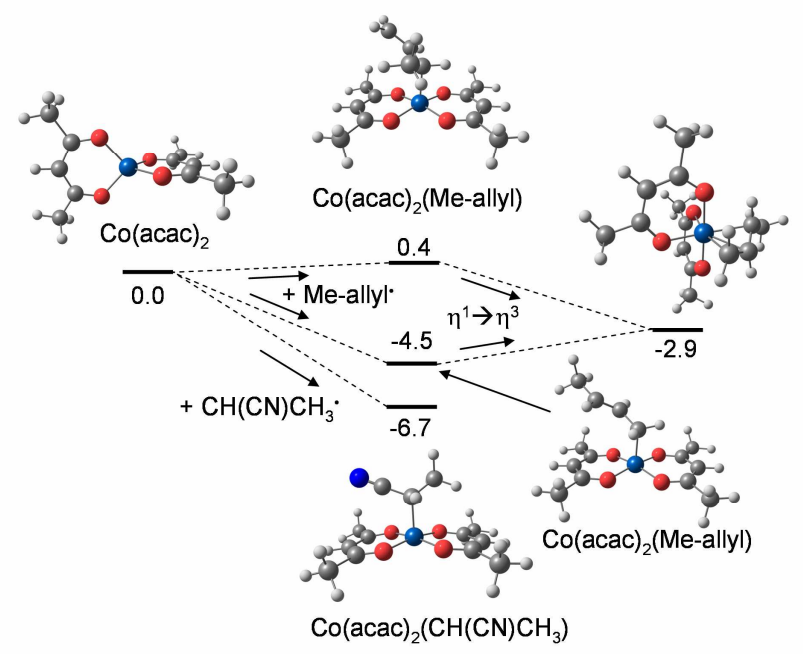

Figure 8. Calculated relative enthalpies (in $\mathrm{kcal} / \mathrm{mol}$ ) and optimized geometries of $\mathrm{Co}(\mathrm{acac})_{2}$ and its addition products with $\mathrm{CH}_{3} \mathrm{CH}(\mathrm{CN})^{\circ}$ and $\mathrm{CH}_{3} \mathrm{CH}=--=\mathrm{CH}=--\mathrm{CH}_{2}$.

The above results already suggest that the allyl radicals are less tightly held by binding to cobalt than the cyanocarbyl radicals. However, the $\mathrm{Co}^{\mathrm{III}}-\mathrm{C}$ BDE can be modulated by the solvent coordination, as demonstrated in our previous contributions. ${ }^{[24,29,38]}$ In the present study, we have restricted our consideration to DMSO as a ligand. Addition of DMSO to the 5-coordinate $\mathrm{Co}^{\mathrm{III}}(\mathrm{acac})_{2}\left(\eta^{1}\right.$ $\left.\mathrm{CH}_{2} \mathrm{CH}=\mathrm{CHCH}_{3}\right)$ species leads to 18-electron $\mathrm{Co}^{\mathrm{III}}(\mathrm{acac})_{2}-$ (DMSO) $\left(\eta^{1}-\mathrm{CH}_{2} \mathrm{CH}=\mathrm{CHCH}_{3}\right)$, with a gain of only $3.2 \mathrm{kcal} / \mathrm{mol}$, whereas addition to $\mathrm{Co}^{\mathrm{III}}(\mathrm{acac})_{2}\left(\mathrm{CH}(\mathrm{CN}) \mathrm{CH}_{3}\right)$ yields $\mathrm{Co}^{\mathrm{III}}(\mathrm{acac})_{2}(\mathrm{DMSO})\left(\mathrm{CH}(\mathrm{CN}) \mathrm{CH}_{3}\right)$ with a gain of $6.6 \mathrm{kcal} / \mathrm{mol}$ (see
Figure 9). Subsequent homolytic cleavage of the $\mathrm{Co}^{\text {III }}-\mathrm{C}$ bonds leads to the common $\mathrm{Co}(\mathrm{acac})_{2}$ (DMSO) intermediate, which is however further stabilized by coordination of a second DMSO molecule.

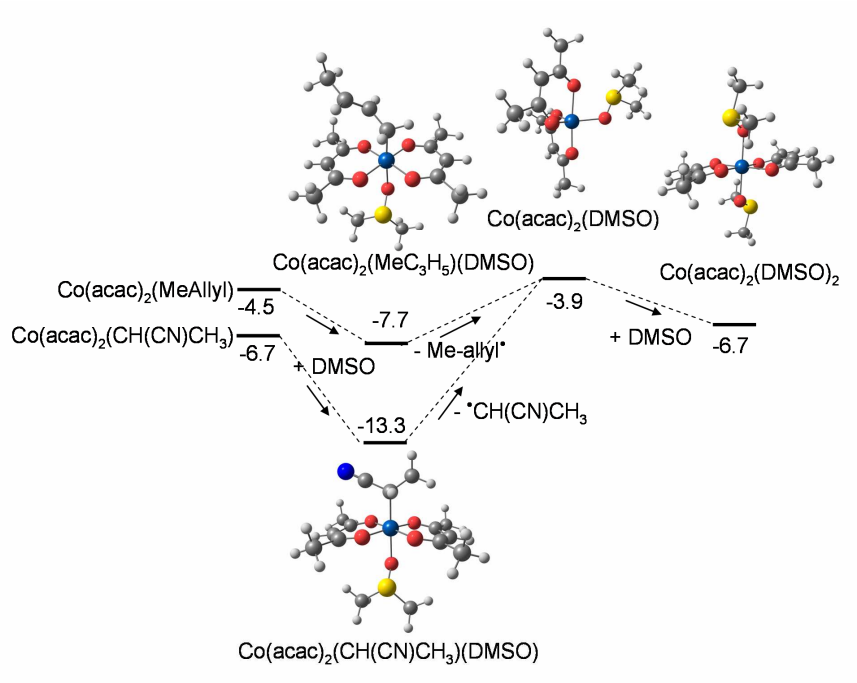

Figure 9. Calculated relative enthalpies (in $\mathrm{kcal} / \mathrm{mol}$ ) and optimized geometries of DMSO adducts for $\mathrm{Co}^{\mathrm{III}}$ and $\mathrm{Co}^{\mathrm{II}}$ compounds of relevance to CMRP and CMRC. Enthalpies shown (in $\mathrm{kcal} / \mathrm{mol}$ ) are relative to the separate $\mathrm{Co}(\mathrm{acac})_{2}$, DMSO, and corresponding free radicals.

According to this calculation, assuming that the results can be extrapolated to the real radical chains and dormant organometallic complexes, the $\mathrm{PAN}^{*}$ chain can be trapped leading to a relatively favoured dormant species, stabilized by $6.6 \mathrm{kcal} / \mathrm{mol}$ relative to the $\mathrm{Co}(\mathrm{acac})_{2}(\mathrm{DMSO})_{2}$ trapping complex, whereas trapping after addition of a butadiene molecule is essentially thermoneutral $\left(\mathrm{CO}^{\mathrm{III}}\right.$ complex stabilized by only $1.0 \mathrm{kcal} / \mathrm{mol}$ ), thus leaving a large free radical concentration at equilibrium. The entropic contribution to these equilibria, which is neglected in the above considerations, is probably not too large because the process involves the same number of species on the two sides of the equilibrium. We prefer, however, to avoid the considerations of the free energy in the condensed phase, because of the uncertainties in the handling of the translational and rotational entropy ${ }^{[39]}$ A correction to the enthalpy values, which derive from gas-phase calculations, for solvation effects is also not expected to change significantly the results because of the low polarity of the compounds.

Discussion: The present contribution has shown that addition of dienes to a Co $\left.\mathrm{CII}_{(\mathrm{acac}}\right)_{2}$-capped PAN leads to efficient radical coupling, for a variety of different diene molecules, yielding polymers that are dominated by PAN-(diene) $)_{2}$-PAN chains. An important experimental result, from the NMR analysis, is the mode of diene insertion, mostly of 1,4-trans type but with a visible small contribution of the 1,2 type. Coming back to the mechanistic issue (section $e$ of Results), the inclusion of only two diene molecules in the dominant portion of the chains indicates that chain propagation is disfavoured relative to either trapping by $\mathrm{Co}(\mathrm{acac})_{2}$ or binuclear coupling. Noteworthy, initiation of isoprene polymerization at $30^{\circ} \mathrm{C}$ by V-70 in the presence of a catalytic or an equimolar amount of $\mathrm{Co}(\mathrm{acac})_{2}$ did not produce specifically the isoprene dimer. Moreover, the molar mass distributions of PIP oligomers collected in the above mentioned experiments were strictly identical to the one produced 
for the same isoprene polymerization conducted in absence of cobalt (see Figure D in supporting information). This experiment suggests that only preformed alkyl-cobalt(III) species can undergo the coupling process. In case trapping to an organometallic $\mathrm{Co}(\mathrm{acac})_{2-}$ capped dormant species would be favoured, the dominant formation of coupled product could be understood under the assumption that the metal-bonded allyl unit is activated toward radical addition. However, two considerations are against this assumption.

The first one is that, according to the DFT calculations, trapping of the allyl radicals is not greatly favoured from the energetic standpoint. The uncertainties and approximations associated to the computations of bond strengths, especially for systems such as this one where the spin state changes on going from reagents to products, certainly do not make of this consideration a very solid one. We expect, however, that the calculations give credible results in terms of trends for systems of the same type and within the same spin state. Thus, even though the absolute BDE values may not be precise, the relative stability of isomers and the relative strength of the $\mathrm{Co}^{\text {III }}$ $\mathrm{CH}_{2} \mathrm{CH}=\mathrm{CHCH}_{3}$ and $\mathrm{Co}^{\mathrm{III}}-\mathrm{CH}(\mathrm{CN}) \mathrm{CH}_{3}$ bonds is to be considered reliable.

The second consideration comes from the observed regiochemistry. Under the assumption that a cobalt(III) dormant species indeed forms, and thus its structure for the butadiene addition product should be $\mathrm{Co}(\mathrm{acac})_{2}(\mathrm{DMSO})\left(\mathrm{CH}_{2} \mathrm{CH}=\mathrm{CHCH}_{2-}\right.$ PAN) as shown for its model system in Figure 9, then the most favourable addition of a second $\mathrm{PAN}-\mathrm{CH}_{2}-\mathrm{CH}=\mathrm{CH}=-\mathrm{CH}_{2}{ }^{\circ}$ radical should take place at the less hindered $\gamma$-carbon atom, as shown in Figure 10, leading to coupled chains with at least one diene monomer inserted in the 1,2 mode. The free radical would probably add predominantly through its less hindered (and more reactive) terminal $\mathrm{C}$ atom $\left(\alpha^{\prime}\right)$. The fact that the dominant diene insertion mode is the 1,4-trans, therefore, casts serious doubts on the cobalt trapping hypothesis.

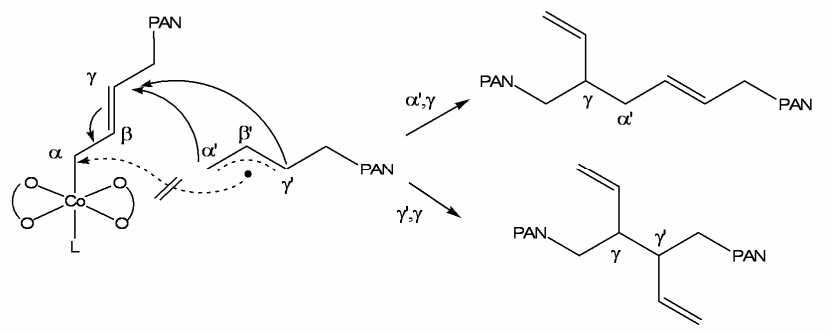

Figure 10. Modes of allyl coupling for a $\mathrm{Co}(\mathrm{acac})_{2}$-capped PAN-allyl chain.

If cobalt trapping is excluded, then how can diene addition lead to efficient coupling instead of further propagation and to a dominant 1,4-trans stereochemistry for the two diene units in the coupled chains? Efficient coupling requires that a large concentration of the free radical chains is generated very rapidly, as in the Atom Transfer Radical Coupling processes from halogenterminated dormant chains in the presence of very active copper catalysts. In fact, we can easily rationalize the fast free radical generation from the $\mathrm{Co}(\mathrm{acac})_{2}(\mathrm{~L})(\mathrm{PAN})$ dormant chains. Under controlled radical PAN growth, we can estimate the rates of activation and deactivation on the basis of the data in Figure 9. The transition state is not necessarily fully dissociative, consisting of the 5 -coordinate $\mathrm{Co}^{\mathrm{II}}(\mathrm{acac})_{2}(\mathrm{~L})$ complex plus the free radical, because solvent molecules are present at large concentration and $\mathrm{Co}^{\mathrm{II}}-\mathrm{L}$ bond formation is probably concerted with $\mathrm{Co}^{\mathrm{III}}$-PAN bond breaking, in a sort of "interchange" mechanism similar to those established for ligand exchange in $\mathrm{Co}{ }^{\mathrm{III}}$ coordination compounds, ${ }^{[40,41]}$ except that in this case a 1-electron ligand (the PAN chain) is replaced by a 2electron ligand (L) while $\mathrm{Co}^{\mathrm{III}}$ becomes $\mathrm{Co}^{\mathrm{II}}$. If this is the case, the barrier corresponding to the Co ${ }^{\text {III }}$-PAN BDE $(9.4 \mathrm{kcal} / \mathrm{mol})$ is a higher estimate for the activation enthalpy, and the activation entropy is expected to be relatively small. Considering this value as a rough estimate for the activation free energy at $298 \mathrm{~K}$, the Eyring equation yields an activation rate constant of ca. $8 \cdot 10^{5} \mathrm{~s}^{-1}$. Trapping, however, is even faster ( $>4 \cdot 10^{10} \mathrm{~s}^{-1}$ if $\Delta \mathrm{G}^{\ddagger}<3 \mathrm{kcal} / \mathrm{mol}$ ), and the equilibrium constant heavily favours the dormant state $\left(\mathrm{K}=1.5 \cdot 10^{-5}\right.$ for the activation process, based on $\Delta \mathrm{G}=6.6 \mathrm{kcal} / \mathrm{mol}$ at $298 \mathrm{~K}$ ).

Upon addition of diene, the rate of allyl radical generation is therefore very high because the activation rate of the $\mathrm{Co}(\mathrm{acac})_{2}(\mathrm{~L})(\mathrm{PAN})$ dormant chains is very high and the rate of diene addition to the resulting $\mathrm{PAN}^{\bullet}$ radical chains is also expected to be very high. However, contrary to the $\mathrm{PAN}^{\circ}$ radicals, the resulting $\mathrm{PAN}-\mathrm{CH}_{2}-\mathrm{CH}=\mathrm{CH}=\mathrm{CH}_{2}{ }^{\cdot}$ radicals are not efficiently trapped by $\mathrm{Co}^{\mathrm{II}}$, see Figure 11 . These radicals will therefore have no other choice than to couple with each other (or to further add diene, but coupling is predominant since the radical concentration is very high). This mechanistic scheme is compatible with the formation of a certain amount of chains containing more than two diene units, which seems to be indicated by the mass spectrometric analysis. On the other hand, it does not predict the formation of chains with less than two diene units, again in harmony with the MS results.

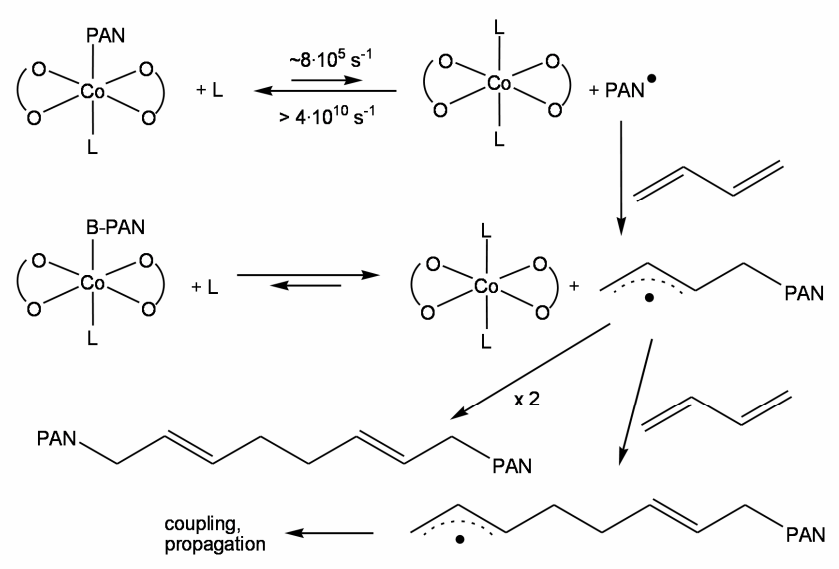

Figure 11. Mechanism of generation of coupled PAN- $B_{n}-P A N$. Only the most probable reactivity at the terminal (primary) position for the allyl radical is shown for simplicity.

For what concerns the regio- and stereochemistry of diene insertion during the CMRC process, it is quite comparable to that of polybutadiene prepared by free radical polymerization. Indeed, a typical free radical polymerization of butadiene mainly follows the 1,4-addition pathway $(1,4$ vs. $1,2: 80 / 20)$ and the trans isomer is much more abundant than the cis isomer (trans vs. cis : 75/25). ${ }^{[2]}$ The similarity of this stereochemistry with that detected in the coupling product corroborates the free radical character of CMRC process.

\section{Conclusion}


We have described a novel radical polymer chain coupling process based on cobalt complexes. Well-defined poly(acrylonitrile) precursors, prepared by CMRP, undergo a nearly quantitative coupling reaction when treated with a large variety of 1,3-diene compounds. In all cases, insertion of few diene units in the middle of the coupling product was observed, of interest for future use in specific mid-chain functionalization. An in-depth examination of the coupling products by NMR and MALDI-ToF, revealed the preferential insertion of two diene units, mainly following a trans1,4 -addition pathway.

On the basis of the evidence collected and with the help of DFT calculations, we propose that CMRC proceeds by a radical mechanism. The ease of cross-propagation from the cyanocarbyl to the allyl radical and the weak propensity of $\mathrm{Co}(\mathrm{acac})_{2}$ to deactivate the allyl radical terminated chains results in the release of a large amount of radical chains in the medium followed by a fast combination reaction instead of diene polymerization.

The efficiency of this radical process, even for poly(acrylonitrile) with quite high molar masses, is unprecedented as well as the precise incorporation of diene units in the middle of the chains which makes the CMRC process quite unique. The ability of CMRC to deal with polymer precursors other than PAN will be investigated and the full potential of this technique will be explored in the near future. Importantly, the impact of this new coupling reaction goes well beyond the field of polymer chemistry and constitutes a novel C-C bond formation method that could be applied to smaller organic molecules for the synthesis of symmetrical derivatives.

\section{Experimental Section}

Materials. Vinyl acetate (>99\%, Aldrich), acrylonitrile (>99\%, Aldrich) and dimethylsulfoxide (DMSO) were dried over calcium hydride, degassed by several freeze-pump-thawing cycles before being distilled under reduced pressure and stored under argon. Compounds 2,2'-azo-bis-(4-methoxy-2,4-dimethyl valeronitrile) (V-70) (Wako), cobalt(II) acetylacetonate (>98\%, Acros) 2,2,6,6-tetramethylpiperidine 1-oxy (TEMPO) (98\%, Aldrich), butadiene, isoprene, 2,4-hexadiene (mixture of isomers, 90\%), 2,3-dimethyl-1,3-butadiene, 1,3-cyclohexadiene (97\%, Aldrich), 2,4-heptadien-1ol (>98\%, Fluka, 95\% trans-trans), benzoic acid, N,N'-dicyclohexylcarbodiimide (99\%, Aldrich), 4-(dimethylamino)pyridine (99\%, Aldrich), cyano-4-hydroxycinnamic acid (CHCA), trans-2-[3-\{4-tert-butylphenyl\}-2-methyl-2-propenylidene]malononitrile (DCTB), dithranol, trans-3-(3-indolyl)acrylic acid and 4-hydroxybenzylidene malononitrile were used as received. Two stock solutions in dichloromethane of the alkyl cobalt(III) adduct initiator $\left(\left[\mathrm{Co}(\mathrm{acac})_{2}\left(-\mathrm{CH}\left(\mathrm{OCOCH}_{3}\right) \mathrm{CH}_{2}\right)_{<4}-\mathrm{R}_{0}\right)\right] ; \mathrm{R}_{0}$ being the primary radical generated by V-70) were prepared as described previously. ${ }^{[26]}$ The cobalt content of these solutions was evaluated by Inductively Coupled Plasma Mass Spectrometry (ICP-MS) ([Co] $=0.122 \mathrm{M}$ and $0.183 \mathrm{M})$.

Characterization. Size exclusion chromatography (SEC) of poly(acrylonitrile) was carried out in dimethylformamide (DMF) containing some $\mathrm{LiBr}(0.025 \mathrm{M})$ at $55^{\circ} \mathrm{C}$ (flow rate : $1 \mathrm{~mL} \mathrm{~min}^{-1}$ ), with a Waters 600 liquid chromatograph equipped with a 410 refractive index detector and styragel HR columns (HR1, 100-5000; HR3, 500-30000; HR4, 5000-500000; HR5, 2000-40000000). Molecular parameters $\left(M_{n}, M_{p}, M_{w} / M_{n}\right)$ were determined by Multi-Angle Laser Light Scattering (MALLS), using $\left(\mathrm{d}_{n} / \mathrm{d}_{\mathrm{c}}\right)$ values determined for each sample by refractometry analysis. However, molecular parameters of PAN samples with short chains $(<3000 \mathrm{~g} / \mathrm{mol})$ were determined by SEC using a PMMA calibration corrected by the Mark-Houwink equation ( $[\eta]=\mathrm{K}_{\mathrm{n}} \mathrm{M}_{\mathrm{n}}{ }^{\mathrm{a}}$, where $\mathrm{K}_{\mathrm{n}}=$ $\left.\mathrm{K}\left(\mathrm{M}_{\mathrm{w}} / \mathrm{M}_{\mathrm{n}}\right)^{0.5 \mathrm{a}(\mathrm{a}+1)}\right)\left(\right.$ in DMF, $\mathrm{K}_{\mathrm{PMMA}}=1.32 \times 10^{-4}, \mathrm{a}_{\mathrm{PMMA}}=0.674 ; \mathrm{K}_{\mathrm{PAN}}=3.17 \times 10^{-4}, \mathrm{a}$ PAN $=0.746) .{ }^{[37,43]}$ Importantly, measurements of the $M_{n}$ and $M_{w} / M_{n}$ for the coupled product were always carried out before precipitation in order to avoid fractionation of the samples. The NMR spectra $\left({ }^{1} \mathrm{H},{ }^{13} \mathrm{C}, \mathrm{HSQC}\right.$ and $\left.\mathrm{HMBC}\right)$ were recorded at $298 \mathrm{~K}$ in DMSO- $d_{6}$ at $600 \mathrm{MHz}\left({ }^{1} \mathrm{H}\right)$ and $150 \mathrm{MHz}\left({ }^{13} \mathrm{C}\right)$ with a Varian instrument and are reported in ppm from internal TMS on the $\delta$ scale. For the HSQC spectrum, 256 scans, D1 of $50 \mu \mathrm{sec}$ and a relaxation delay of $1 \mathrm{sec}$ were used. For the HMBS spectrum, 200 scans, D1 of $50 \mu \mathrm{sec}$ and a relaxation delay of $1 \mathrm{sec}$ were used. The ${ }^{13} \mathrm{C}$ spectrum was recorded at $298 \mathrm{~K}$ with a Bruker spectrometer $(400 \mathrm{MHz})$. MALDI mass spectra were recorded using a Waters QToF Premier mass spectrometer equipped with a nitrogen laser, operating at $337 \mathrm{~nm}$ with a maximum output of $500 \mathrm{~J} / \mathrm{m}^{2}$ delivered to the sample in $4 \mathrm{~ns}$ pulses at $20 \mathrm{~Hz}$ repeating rate. Time-of-flight mass analyses were performed in the reflectron mode at a resolution of about 10000 . The matrix was prepared as 10 $\mathrm{mg} / \mathrm{mL}$ solution in THF. The matrix solutions $(1 \mu \mathrm{L})$ were applied to a stainless steel target and air dried. Polymer samples were dissolved in DMSO to obtain $1 \mathrm{mg} / \mathrm{mL}$ solutions. $1 \mu \mathrm{L}$ aliquots of these solutions were applied onto the target area already bearing the matrix crystals, and then air dried. Finally, $1 \mu \mathrm{L}$ of a solution of $\mathrm{NaI}(2$ $\mathrm{mg} / \mathrm{mL}$ in acetonitrile: water (1:1)) was applied onto the target plate. For the recording of the single-stage ESI-MS spectra, the quadrupole (rf-only mode) was set to pass ions from 700 to $2250 \mathrm{Th}$, and all ions were transmitted into the pusher region of the timeof-flight analyzer where they were mass analyzed with $1 \mathrm{~s}$ integration time. Data were acquired in continuum mode until acceptable averaged data were obtained.

General procedure for the radical coupling of poly(acrylonitrile) with molar mass below $5000 \mathrm{~g} / \mathrm{mol}$. All polymerization and coupling reactions were carried out under a protective argon atmosphere using distilled and degassed monomers and solvents. A solution of alkyl-cobalt(III) initiator ([Co(acac) $\left.\left.2\left(-\mathrm{CH}\left(\mathrm{OCOCH}_{3}\right) \mathrm{CH}_{2}\right)_{<4}-\mathrm{R}_{0}\right)\right]$ in $\mathrm{CH}_{2} \mathrm{Cl}_{2}$ was introduced under argon in a Schlenk tube $(1.0 \mathrm{~mL}$ of a $0.122 \mathrm{M}$ stock solution, 0.12 $\mathrm{mmol}$ ) and evaporated to dryness under reduced pressure at room temperature. The residue was dissolved under argon in DMSO $(2.5 \mathrm{~mL})$ and to the resulting solution was added $\mathrm{AN}(2.5 \mathrm{~mL} 1,2.0 \mathrm{~g}, 38 \mathrm{mmol})([\mathrm{AN}] /[\mathrm{Co}]=310)$ at room temperature. The Schlenk tube was then immersed in an ice-bath and stirred for $4 \mathrm{~h}$ at $0^{\circ} \mathrm{C}$. An aliquot was then withdrawn in order to evaluate the AN conversion by ${ }^{1} \mathrm{H}$ NMR $(18 \%)$ and to measure the molecular parameters of the PAN by SEC-MALLS $\left(M_{n \text { MALLS }}=4080 \mathrm{~g} / \mathrm{mol}\right.$, $\mathrm{M}_{\mathrm{w}} / \mathrm{M}_{\mathrm{n}}=1.02$ ). Monomer conversion was maintained sufficiently low to prepare a polymer with low molar mass in order to facilitate the NMR analysis. After removal of the unreacted AN under reduced pressure at r.t., the reaction medium was treated with butadiene $(5.0 \mathrm{mmol}, 0.27 \mathrm{~g}, 0.45 \mathrm{~mL})$ and stirred for $1 \mathrm{~h}$ at r.t.. An aliquot was then withdrawn in order to characterize the resulting PAN by SEC-MALLS $\left(\mathrm{M}_{\mathrm{n} \text { MALLS }}=8650\right.$ $\mathrm{g} / \mathrm{mol}, \mathrm{M}_{\mathrm{w}} / \mathrm{M}_{\mathrm{n}}=1.02$ ) before purification of the coupling product by repeated precipitation in a $\mathrm{MeOH} / \mathrm{H}_{2} \mathrm{O}(20 / 80)$ mixture and drying under vacuum at $70^{\circ} \mathrm{C}$.

All coupling experiments were carried out following the exact same procedure using different dienes. When 2,4-heptadienyl benzoate 7 was used as coupling agent, the PAN was recovered by subsequent precipitation in a $\mathrm{MeOH} / \mathrm{H}_{2} \mathrm{O}(20 / 80)$ mixture and in pure methanol.

General procedure for the radical coupling of poly(acrylonitrile) with molar mass above $10000 \mathrm{~g} / \mathrm{mol}$. All polymerization and coupling reactions were carried out under a protective argon atmosphere using distilled and degassed monomers and solvents. A solution of alkyl-cobalt(III) initiator ([Co(acac) $\left.\left.)_{2}\left(-\mathrm{CH}\left(\mathrm{OCOCH}_{3}\right) \mathrm{CH}_{2}\right)_{<4}-\mathrm{R}_{0}\right)\right]$ in $\mathrm{CH}_{2} \mathrm{Cl}_{2}$ was introduced under argon in a Schlenk tube $(0.50 \mathrm{~mL}$ of a $0.183 \mathrm{M}$ stock solution, $0.092 \mathrm{mmol}$ ) and evaporated to dryness under reduced pressure at r.t.. The residue was then placed under argon at $0^{\circ} \mathrm{C}$ and added with a mixture of DMSO $(1.25 \mathrm{~mL})$, DMF $(1.25 \mathrm{~mL})$ and $\mathrm{AN}(2.5 \mathrm{~mL}, 2.0 \mathrm{~g}, 38 \mathrm{mmol})$ previously cooled at $0^{\circ} \mathrm{C}([\mathrm{AN}] /[\mathrm{Co}]=$ 422). The reaction medium was then stirred for $24 \mathrm{~h}$ at $0^{\circ} \mathrm{C}$. An aliquot was withdrawn in order to evaluate the AN conversion by ${ }^{1} \mathrm{H}$ NMR (37\%) and to measure the molecular parameters of the PAN by SEC-MALLS $\left(\mathrm{M}_{\mathrm{n} \text { MALLS }}=11000 \mathrm{~g} / \mathrm{mol}, \mathrm{M}_{\mathrm{w}} / \mathrm{M}_{\mathrm{n}}=1.02\right)$. After removal of the unreacted $\mathrm{AN}$ under reduced pressure at r.t., the reaction medium was diluted with DMF $(2.0 \mathrm{~mL})$, treated with butadiene $(5.0 \mathrm{mmol}, 0.27 \mathrm{~g}, 0.45 \mathrm{~mL})$ and stirred for $2 \mathrm{~h}$ at r.t.. A second aliquot was withdrawn in order to characterize the PAN by SEC-MALLS $\left(\mathrm{M}_{\mathrm{n} \text { MALLS }}=21200 \mathrm{~g} / \mathrm{mol}, \mathrm{M}_{\mathrm{w}} / \mathrm{M}_{\mathrm{n}}=1.01\right)$ before purification of the coupling product by repeated precipitation in a $\mathrm{MeOH} / \mathrm{H}_{2} \mathrm{O}(20 / 80)$ mixture and drying under vacuum at $70^{\circ} \mathrm{C}$

All coupling experiments were carried out following exactly the same procedure using $5.0 \mathrm{mmol}$ of each diene, with the exception of the coupling experiment carried out with 2,4-heptadienyl benzoate 7 . In this case, the coupling agent $(2.5 \mathrm{mmol})$ was previously dissolved in $1 \mathrm{~mL}$ of degassed DMF before injection.

CMRC of homopoly(acrylonitrile) precursors prepared by CMRP with V-70 as initiator. $\mathrm{Co}(\mathrm{acac})_{2}(0.600 \mathrm{~g}, 2.34 \mathrm{mmol})$ and $\mathrm{V}-70(0.720 \mathrm{~g}, 2.34 \mathrm{mmol})$ were introduced into a round bottom flask capped by a three-way stopcock and purged by three vacuum-argon cycles. After subsequent addition of distilled and degassed DMSO $(15.0 \mathrm{~mL})$ and $\mathrm{AN}(15.0 \mathrm{~mL}, 12.1 \mathrm{~g}, 228 \mathrm{mmol})$, the reaction medium was heated at $30^{\circ} \mathrm{C}$ under stirring $([\mathrm{AN}] /[\mathrm{Co}]=97)$. After $1 \mathrm{~h}$, a sample was withdrawn. Few drops of the sample were diluted in deuterated DMSO containing TEMPO in order to measure the AN conversion by ${ }^{1} \mathrm{H}$ NMR $\left(298 \mathrm{~K}, \mathrm{D}_{1}=2 \mathrm{~s}, 16\right.$ scans) ( $\mathrm{AN}$ convn $=10 \%$ ). Monomer conversion was maintained sufficiently low in order to prepare a low molar mass polymer for the ease of MALDI-TOF MS analysis. Half of the reaction medium was precipitated in methanol. The recovered polymer was dried under vacuum at $70^{\circ} \mathrm{C}$ before measuring its molecular parameters by SEC $\left(M_{n \text { SEC }}=1900 \mathrm{~g} / \mathrm{mol}, M_{w} / M_{n}=\right.$ 1.21). Then, unreacted AN was removed from the polymerization medium under vacuum at r.t. before addition of isoprene $(1.0 \mathrm{~mL}, 0.68 \mathrm{~g}, 10 \mathrm{mmol})$ and stirred at room temperature for 1 hour. After removing the residual isoprene under vacuum, the polymer was precipitated by addition of methanol. The resulting PAN was characterized by $\operatorname{SEC}\left(M_{n \text { SEC }}=3100 \mathrm{~g} / \mathrm{mol}, M_{w} / M_{n}=1.31\right)$. After purification, the final PAN was analyzed by MALDI-ToF mass spectrometry. Molar masses of the above mentioned PAN samples were determined by SEC using a PMMA calibration corrected by the Mark-Houwink equation.

Synthesis of 2,4-heptadienyl benzoate 7. 2,4-heptadiene-1-ol 6 ( $2.24 \mathrm{~g}, 20.0 \mathrm{mmol})$ was introduced in a round bottom flask, dissolved in dichloromethane $(20.0 \mathrm{~mL})$ at room temperature and to the resulting solution were added benzoic acid $(2.44 \mathrm{~g}, 20.0$ mmol), dicyclohexyl carbodiimide (DCC) $(5.00 \mathrm{~g}, 24.0 \mathrm{mmol})$ and dimethylaminopyridine (DMAP) $(0.25 \mathrm{~g}, 2.0 \mathrm{mmol})$. The reaction mixture was then 
stirred for $4 \mathrm{~h}$ at room temperature. The white precipitate formed during the reaction was removed by filtration. The reaction medium was then extracted with a dichloromethane/water mixture. The organic layer was recovered, dried over magnesium sulfate, filtered and evaporated to dryness under reduced pressure. After purification by chromatography on silica using dichloromethane as eluent $(\mathrm{rf}=0.8)$, a colorless product was recovered $(2.9 \mathrm{~g}$, yield $=67 \%)$. ${ }^{1} \mathrm{H}$ NMR $\left(400 \mathrm{MHz}, \mathrm{CDCl}_{3}\right) \delta$ : $8.40-7.76$ (m, $2 \mathrm{H}$ arom.), $7.80-7.30$ (m, $3 \mathrm{H}$ arom.), 6.35 (dd, $J=15.1,10.4 \mathrm{~Hz}, 1 \mathrm{H}$ vinyl.), 6.07 (dd, $J=15.1,10.5 \mathrm{~Hz}, 1 \mathrm{H}$ vinyl.), 5.79 (m, $2 \mathrm{H}$ vinyl.), 4.84 (d, $J=7.6 \mathrm{~Hz}$ $2 \mathrm{H},-\mathrm{CH}_{2}$-OCOPh), 2.12 (m, 2H allyl.), 1.02 (t, $J=7.5 \mathrm{~Hz}, 3 \mathrm{H}$ aliph.). ${ }^{13} \mathrm{C}$ NMR (400 $\left.\mathrm{MHz}, \mathrm{CDCl}_{3}\right) \delta: 166.39,138.33,135.11,132.90,130.34,129.63,128.33,128.16$, $124.02,65.44,25.66,13.36$.

Computational details. All geometry optimizations were performed using the B3LYP three-parameter hybrid density functional method of Becke, ${ }^{[44]}$ as implemented in the Gaussian03 suite of programs. ${ }^{[45]}$ The basis functions consisted of the standard 6-31G** for all light atoms $(\mathrm{H}, \mathrm{C}, \mathrm{N}, \mathrm{O})$, plus the LANL2DZ function, which included the Hay and Wadt effective core potentials (ECP) and an $f$ polarization function $(\alpha=0.8)$, for Co. All geometry optimizations were carried out without any symmetry constraint and all final geometries were characterized as local minima of the potential energy surface (PES) by verifying that all second derivatives of the energy were positive. The unrestricted formulation was used for open-shell molecules. The value of $\left\langle\mathrm{S}^{2}\right\rangle$ at convergence was very close to the expected value of 0.75 for the radical species and 3.75 for the spin quartet species [the greatest deviation was 3.760 for complex $\left.\mathrm{Co}(\mathrm{acac})_{2}(\mathrm{DMSO})_{2}\right]$, indicating minor spin contamination. All energies were corrected for zero point vibrational energy and for thermal energy to obtain the bond dissociation enthalpies at $298 \mathrm{~K}$. The standard approximations for estimating these corrections were used (ideal gas, rigid rotor and harmonic oscillator) as implemented into Gaussian03. Additional calculations were also carried out with the same basis set by use of the B3PW91* functional, at the fixed geometries optimized by B3LYP. The thermal enthalpy correction was carried out using the B3LYP values. The B3PW91* functional is a modified version of the B3PW91 functional, in which the $c_{3}$ coefficient in Becke's original three-parameter fit to thermochemical data was changed to 0.15 .

\section{Acknowledgements}

The "Belgian Science Policy" in the frame of the "Interuniversity Attraction Poles Programme" (PAI VI/27) is acknowledged for financial support. A.D. (FRS-FNRS Postdoctoral Researcher) and C.D. (FRS-FNRS Senior Research Associate) are grateful to the "Fonds National de la Recherche Scientifique" (FRS-FNRS) for financial support and for the acquisition of SEC DMF (convention "Crédit aux Chercheurs" $\mathrm{n}^{\circ}$ 1.5.006.06) and MALLS detector (convention F.R.F.C. $\mathrm{n}^{\circ} 2.4541 .07$ ). P.G. and J.D.W. (FRS-FNRS research associate and research fellow) are grateful to the FRSFNRS for financial support in the acquisition of the Waters QtoF Premier mass spectrometer and for continuing support. The authors thank G. Cartigny for skilful assistance. R.P. thanks the CNRS and the IUF for funding and the CICT (Project CALMIP) for granting free computational time.

[1] W. A. Braunecker, K. Matyjaszewski, Prog. Polym. Sci. 2007, 32 (1), 93-146.

[2] M. Kamigaito, T. Ando, M. Sawamoto, Chem. Rev. 2001, 101, 3689-3745.

[3] C. J. Hawker, A.W. Bosman, E. Harth, Chem. Rev. 2001, 101 (12), 3661-3688.

[4] V. Sciannamea, R. Jerome, C. Detrembleur, Chem. Rev. 2008, 108 (3), 1104 1126.

[5] C. Barner-Kowollik, "Handbook of RAFT polymerization", Ed. Wiley VCH, 2008.

[6] G. Moad, E. Rizzardo, S. H. Thang, Acc. Chem. Res. 2008, 41 (9), 1133-1142.

[7] J. Qiu, B. Charleux, K. Matyjaszewski, Prog. Polym. Sci. 2001, 26 (10), $2083-$ 2134

[8] M. F. Cunningham, Prog. Polym. Sci. 2008, 33 (4), 365-398.

[9] P. B. Zetterlund, Y. Kagawa, M. Okubo, 2008, 108 (9), 3747-3794

[10] A. Debuigne, R. Poli, C. Jerome, R. Jerome, C. Detrembleur, Prog. Polym. Sci. 2009, 34 (3), 211-239.

[11] S. Yamago, Chem. Rev. 2009, doi: 10.1021/cr9001269.

[12] S. Yurteri, I. Cianga, Y. Yagci, Macromol. Chem. Phys. 2003, 204 (14), 17711783 .

[13] T. Sarbu, K.-Y. Lin, J. Spanswick, R. R. Gil, D. J. Siegwart, K. Matyjaszewski, Macromolecules 2004, 37 (26), 9694-9700.

[14] T. Sarbu, K.-Y. Lin, J. Ell, D. J. Siegwart, J. Spanswick, K. Matyjaszewski, Macromolecules 2004, 37 (9), 3120-3127.

[15] R. Nagelsdiek, H. Keul and H. Hoecker, e-Polym. 2005, $\mathrm{N}^{\circ} 049$

[16] B. Otazaghine, C. Boyer, J.-J. Robin, B. Boutevin, J. Polym. Sci., Part A: Polym. Chem. 2005, 43 (11), 2377-2394.
[17] B. Nottelet, P. Lacroix-Desmazes, B. Boutevin, Polymer 2007, 48 (1), 50-57.

[18] J. T. Kopping, Z. P. Tolstyka, H. D. Maynard, Macromolecules 2007, 40 (24), 8593-8599.

[19] A. Debuigne, C. Jerome, C. Detrembleur, Angew. Chem., Int. Ed. 2009, 48 (8), 1422-1424.

[20] B. B. Wayland, G. Poszmik, S. L. Mukerjee, M. Fryd, J. Am. Chem. Soc. 1994, 116 (17), 7943-4.

[21] Z. Lu, M. Fryd, B. B. Wayland, Macromolecules 2004, 37 (8), 2686-2687.

[22] A. Debuigne, J.-R. Caille, R. Jerome, Angew. Chem. 2005, 44 (7), 1101-1104.

[23] A. Debuigne, J.-R. Caille, C. Detrembleur, R. Jerome, Angew. Chem. 2005, 44 (22), 3439-3442.

[24] S. Maria, H. Kaneyoshi, K. Matyjaszewski, R. Poli, Chem. Eur. J. 2007, 13 (9), 2480-2492.

[25] C.-H. Peng, J. Scricco, S. Li, M. Fryd, B. B. Wayland, Macromolecules 2008, 41 (7), 2368-2373.

[26] A. Debuigne, Y. Champouret, R. Jerome, R. Poli, C. Detrembleur, Chem. Eur. J. 2008, 14 (13), 4046-4059.

[27] H. Kaneyoshi, K. Matyjaszewski, Macromolecules 2006, 39 (8), 2757-2763.

[28] A. Debuigne, N. Willet, R. Jerome, C. Detrembleur, C., Macromolecules 2007, 40 (20), 7111-7118.

[29] A. Debuigne, C. Michaux, C. Jerome, R. Jerome, R. Poli, C. Detrembleur, Chem. Eur. J. 2008, 14 (25), 7623-7637.

[30] A. Debuigne, J. Warnant, R. Jerome, I. Voets, A. de Keizer, A., M. A. Cohen Stuart, C. Detrembleur, Macromolecules 2008, 41 (7), 2353-2360.

[31] K. Linnemayr, P. Vana, G. Allmaier, Rapid Commun. Mass Spectrom. 1998, 12 (19), 1344-1350

[32] M. Takayam, J. Am. Soc. Mass Spectrom. 2001, 12 (9), 1044-1049.

[33] Y. Fukuyama, S. Iwamoto, K. Tanaka, J. Mass Spectrom. 2006, 41 (2), 191-201.

[34] A. D. H. Clague, J. A. M. Van Broekhoven, L. P. Blaauw, Macromolecules 1974, 7 (3), 348-54

[35] G. Van der Velden, C. Didden, T. Veermans, J. Beulen, Macromolecules 1987, 20 (6), 1252-1256.

[36] T. Ishihara, T. Shiono, Macromolecules 2003, 36 (26), 9675-9677.

[37] J. Brandrup, E. H. Immergut, "Polymer Handbook, Fourth Edition" 1999.

[38] A. Debuigne, R. Poli, R. Jerome, C. Jerome, C. Detrembleur, ACS Symp. Ser. 2009, 1024, 131-148.

[39] C. J. Cramer, D. G. Truhlar, Acc. Chem. Res. 2008, 41, 760

[40] F. Basolo, in "Mechanisms of Inorganic Reactions", Ed. R. F. Gould, Washington, D.C. 1965.

[41] J. D. Atwood, in "Inorganic and Organometallic Reaction Mechanisms, Brooks/Cole Publishing Co. 1985

[42] K. Matyjaszewski, T. P. Davis, "Handbook of Radical Polymerization", Ed. John Wiley and Sons 2002, 904 pages

[43] X.-H. Liu,Y.-G. Li, Y. Lin, Y.-S. Li, J. Polym. Sci., Part A: Polym. Chem. 2007, 45 (7), 1272-1281.

[44] A. D. Becke, J. Chem. Phys. 1993, 98 (7), 5648-52.

[45] M. J. Frisch, G. W. Trucks, H. B. Schlegel, G. E. Scuseria, M. A. Robb, J. R Cheeseman, J. Montgomery, J. A., T. Vreven, K. N. Kudin, J. C. Burant, J. M. Millam, S. S. Iyengar, J. Tomasi, V. Barone, B. Mennucci, M. Cossi, G. Scalmani, N. Rega, G. A. Petersson, H. Nakatsuji, M. Hada, M. Ehara, K. Toyota, R. Fukuda, J. Hasegawa, M. Ishida, T. Nakajima, Y. Honda, O. Kitao, H. Nakai, M. Klene, X. Li, J. E. Knox, H. P. Hratchian, J. B. Cross, C. Adamo, J. Jaramillo, R. Gomperts, R. E. Stratmann, O. Yazyev, A. J. Austin, R. Cammi, C Pomelli, J. W. Ochterski, P. Y. Ayala, K. Morokuma, G. A. Voth, P. Salvador, J. J. Dannenberg, V. G. Zakrzewski, S. Dapprich, A. D. Daniels, M. C. Strain, O. Farkas, D. K. Malick, A. D. Rabuck, K. Raghavachari, J. B. Foresman, J. V. Ortiz, Q. Cui, A. G. Baboul, S. Clifford, J. Cioslowski, B. B. Stefanov, G. Liu, A. Liashenko, P. Piskorz, I. Komaromi, R. L. Martin, D. J. Fox, T. Keith, M. A. Al-Laham, C. Y. Peng, A. Nanayakkara, M. Challacombe, P. M. W. Gill, B. Johnson, W. Chen, M. W. Wong, C. Gonzalez, J. A. Pople, Gaussian 03, Revision C.02, Gaussian, Inc., Wallingford CT. Gaussian 03, Revision C.02, Gaussian, Inc., Wallingford CT 2004.

Received: ((will be filled in by the editorial staff)) Revised: ((will be filled in by the editorial staff)) Published online: ((will be filled in by the editorial staff)) 
Table of Contents

Radical Polymer Coupling

A. Debuigne, * R. Poli, J. De Winter, P. Laurent, P. Gerbaux, P. Dubois, J.-P. Wathelet, C. Jérôme, $C$.

Detrembleur... Page - Page

Cobalt-Mediated Radical

Coupling (CMRC) : An Unusual

Route to Mid-Chain

Functionalized Symmetrical Macromolecules
Subsequent controlled radical polymerization and radical coupling reaction based on cobalt complexes (CMRP \& CMRC) lead to welldefined mid-chain functionalized symmetrical polymers. New synthetic possibilities, structure of the coupling products, as well as CMRC mechanism were examined through a magnifying glass. 